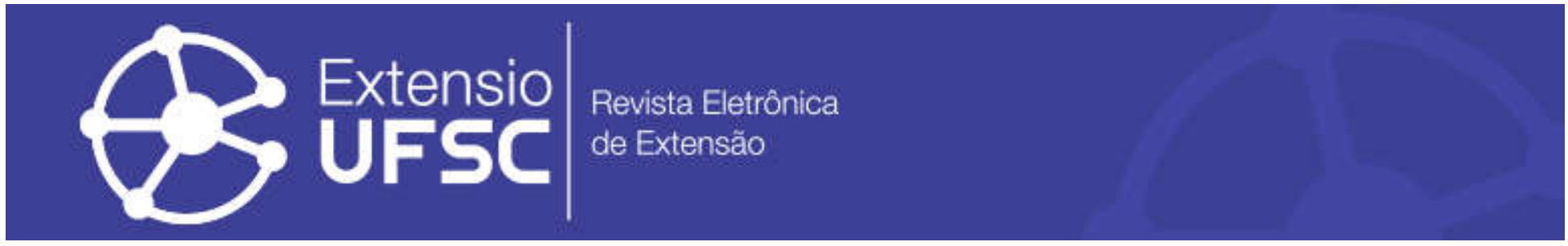

\title{
PROJETO DE EXTENSÃO “GESTÃO DE SERVIÇOS EM INSTITUIÇÕES DO TERCEIRO SETOR"
}

\author{
Ana Regina Bezerra Ribeiro \\ Universidade Federal Rural de Pernambuco \\ anaregina.ribeiro@ufrpe.br \\ Natália Lúcia da Silva Pinto \\ Universidade Federal Rural de Pernambuco \\ natalialuciapinto@gmail.com \\ Lara Régia Melo Filho \\ Instituto Federal de Educação, Ciência e Tecnologia de Pernambuco \\ lararmf@gmail.com \\ Marcela Correia Gomes Barbosa Ayres \\ Universidade Federal Rural de Pernambuco \\ marcelaayres@live.com \\ Suellen Araújo Oliveira \\ Universidade Federal Rural de Pernambuco \\ su.araujoliveira@gmail.com
}

\begin{abstract}
Resumo
O presente trabalho enfoca as atividades desenvolvidas pelo projeto de extensão da Universidade Federal Rural de Pernambuco intitulado "Gestão de Serviços em Instituições do Terceiro Setor", cuja vigência foi de janeiro a dezembro de 2017. O projeto teve como objetivo inserir e aproximar os estudantes da graduação e do mestrado em Administração no contexto das organizações do terceiro setor (OTS) e proporcionar melhorias na prestação de serviços das ONGs beneficiadas. O projeto foi pautado nas finalidades das atividades de extensão, ou seja, na integração com as atividades de ensino e pesquisa para atender às demandas da sociedade, respeitando o compromisso social da universidade e permitindo uma maior interligação entre os ambientes acadêmico e comunitário. O projeto foi dividido em três etapas distintas: a seleção das instituições, o diagnóstico organizacional e a execução de ações. A metodologia permitiu o planejamento e execução de ações em cinco instituições. Foi observada a dificuldade de atender à demanda destas, devido às diferenças do público-alvo. Contudo, o projeto de extensão proporcionou à equipe executora o entendimento da dinâmica das organizações deste segmento, analisando suas diferenças, afinal, se forem comparadas às instituições privadas ou públicas, as organizações do terceiro setor não têm a lucratividade como finalidade, possuem voluntários contribuindo para a prestação de serviços e, na maioria das vezes, não têm mecanismos de gestão adequados à sua realidade. Ao fim do projeto, verificou-se que houve promoção do conhecimento sobre gestão administrativa, melhoria na qualidade dos serviços prestados e no relacionamento interpessoal entre os membros das cinco instituições atendidas pelo projeto de extensão.
\end{abstract}

Palavras-chave: Projeto de Extensão Universitária. Terceiro Setor. Gestão de Serviços.

\section{EXTENSION PROJECT “SERVICE MANAGEMENT IN THIRD SECTOR INSTITUTIONS"}

\begin{abstract}
This work reports the activities developed by the extension project of the Federal Rural University of Pernambuco entitled "Service Management in Third Sector Institutions", realized from January to December 2017. The project aimed to insert and bring under graduate and master's in Administration students closer to the context of third sector organizations (OTS) and to provide improvements in the provision of services of the NGOs. The project was based on the purposes of extension activities, on integration with teaching and research activities to meet society's demands, respecting the university's social commitment and allowing interconnection between the academic and community environments. The project was divided into three distinct stages: the selection of institutions; the organizational
\end{abstract}


diagnosis and the execution of actions. The methodology contributed to the planning and execution of actions in five institutions. It was observed the difficulty to meet their demand due to differences in the target audience. However, the extension project provided the executing team with an understanding of the dynamics of organizations in this segment, analyzing their differences, after all, if compared to private or public institutions, third sector organizations do not have profitability as their purpose, they have volunteers contributing to the provision of services and, in most cases, they do not have management mechanisms adequate to their reality. At the end of the project, it was found that there was promotion of knowledge about administrative management, improvement in the quality of the services provided and in the interpersonal relationship between the members of the five institutions served by the extension project.

Keywords: University Extension Project. Third Sector. Service Management.

\title{
PROYECTO DE EXTENSIÓN “GESTIÓN DE SERVICIOS EN INSTITUCIONES DEL TERCER SECTOR”
}

\begin{abstract}
Resumen
El trabajo informa sobre las actividades desarrolladas em el proyecto de extensión de La Universidade Federal Rural de Pernambuco cuyo el nombre es "Gestión de servicios em Instituciones del Tercer Sector" que se pasó entre enero y diciembre de 2017. El proyecto tuvo como objetivo insertar y reunir estudiantes de pregrado y magister em Administración em el contexto de las organizaciones del tercer sector y proporcionar mejoras em la prestación de los servicios de las ONGs beneficiadas. El proyecto se basó em los propósitos de actividades de extensión, o sea, em la integración com actividades de enseñanza e investigación para satisfacer las necesidades de las ociedad, respectando el compromiso social de la Universidad y generando una mayor interconexión entre los entornos académicos y comunitarios. El proyecto fue estructurado entres etapas distintas: selección de las instituciones; la diagnosis organizacional y la ejecución de acciones. La metodologia permitió el planeamiento y ejecución en cinco instituciones. La dificultad de satisfacer demandas fue observada debidolas diferencias em el público objetivo. Mientras, el proyecto de extensión proporciono al equipo ejecutor una comprensión de la dinámica de las organizaciones en este segmento, analizando sus diferencias, después de todo, si se compara com las instituciones privadas o públicas, las organizaciones del tercer sector no tienen como objetivo la rentabilidad, tienen voluntarios que contribuyen a laprovisión de servicios y, em la mayoría de los casos, no cuentan con mecanismos de gestión adecuados a surealidad. Al fin del proyecto, fue verificado que hube promoción de conocimiento sobre la gestión administrativa, mejoría em la calidad de los servicios de las instituciones y em las relaciones interpersonales de los miembros de las cinco instituciones asistidas por el proyecto de extensión.
\end{abstract}

Palabras clave: Proyecto de Extensión Universitaria. Tercer Sector. Gestión de Servicios. 


\section{INTRODUÇÃO}

É notório o desfavorecimento das classes mais baixas perante os serviços básicos no Brasil, sejam eles de assistência social, educação, segurança ou de saúde. Com isso, eleva-se a importância de ações beneficentes advindas, em sua maioria, das instituições de terceiro setor no país. As Universidades públicas, por sua vez, possuem o dever de, também, colaborar com o desenvolvimento social através da disseminação do conhecimento gerado dentro da academia. Sendo assim, elas desenvolvem projetos de cunho social dentro de seus três pilares indissociáveis: ensino, pesquisa e extensão.

Os projetos de Extensão Universitária, como o próprio nome sugere, têm por finalidade estender à comunidade não universitária os conhecimentos e habilidades da academia, através de ações contínuas e sequenciais de caráter socioeducativo, científico e/ou tecnológico. E, o Terceiro Setor, objetiva fornecer serviços para a sociedade a fim de minimizar os impactos sociais negativos mediante a execução de atividades políticoeconômicas e/ou socioculturais nos ambientes em que atuam.

Ao observar as organizações pertencentes ao terceiro setor e o modo como prestam os serviços, torna-se necessário abordar a questão da qualidade na prestação de serviços, para que, mesmo com poucos recursos, estas organizações estejam focadas em atingir os padrões de qualidade necessários para a oferta de serviços. E para que, consequentemente, beneficiários, financiadores e demais parceiros e a sociedade civil reconheçam o trabalho desenvolvido.

Diante do exposto, este artigo busca enfocar e relatar as atividades desenvolvidas pelo projeto de extensão intitulado "Gestão de Serviços em Instituições do Terceiro Setor", realizado por membros do Departamento de Administração da Universidade Federal Rural de Pernambuco. Seu propósito foi promover ações de consultoria e capacitação em gestão de serviços para os colaboradores de cinco instituições não governamentais selecionadas, objetivando proporcionar melhorias na prestação de seus principais serviços, em busca do crescimento sustentável das ONGs localizadas na Região Metropolitana do Recife - RMR.

A proposta deste artigo enquadra-se na temática das relações entre estado e sociedade, uma vez que aborda questões relativas às organizações do terceiro setor e suas relações com os demais setores, caso do presente texto, que trata de uma iniciativa de extensão com instituição de ensino superior federal e ONGs da cidade do Recife. Tal proposta contou com ações que contribuem para a aplicação do conhecimento difundido no âmbito do curso de Bacharelado em Administração e fazem a integração entre a graduação e a pós-graduação, revelando a importância para a tríade ensino-pesquisa-extensão. 
Este artigo é composto por cinco partes. A primeira, a introdução, traz os primeiros contatos com objeto de estudo e os objetivos. A segunda etapa traz as principais concepções que serviram de referência para nortear o trabalho, como terceiro setor e qualidade na gestão de serviços. A terceira, a metodologia, que aponta os procedimentos realizados para a elaboração deste relato. A quarta, com os principais resultados auferidos com o projeto de extensão. E, por fim, as considerações finais, que traz uma reflexão sobre a execução do projeto, com os seus pontos positivos e negativos.

\section{REFERENCIAL TEÓRICO}

As Organizações Não Governamentais (ONGs) não têm o lucro como a finalidade e são direcionadas ao atendimento das necessidades da sociedade civil, contribuindo com a ação do Estado e de outros agentes econômicos que muitas vezes não conseguem atender as demandas da sociedade. As ONGs têm o financiamento de suas ações advindos de agências e outras ONGs internacionais, do governo e do setor privado, têm a presença de voluntários no seu quadro de funcionários para a atuação na promoção de direitos sociais (TENÓRIO, 2009).

No debate conceitual, cabe abordar que as organizações sem fins lucrativos exercem diferentes papéis nas suas relações com o Estado e com as empresas e a sociedade civil. Essas instituições podem agir na execução e no controle de políticas públicas, estabelecendo parcerias através das trocas entre os setores socioeconômicos (TEODÓSIO, 2002). As ações de colaboração com o Estado e com o setor empresarial podem fornecer benefícios, tangíveis e intangíveis, que favorecem a manutenção organizacional (AL-TABBA, LEACH E MARCH, 2014).

Ainda no enfoque do debate conceitual, faz-se necessário contemplar o posicionamento de autores como Montaño (2007), cuja contribuição consiste em tratar o terceiro setor como uma tentativa do Estado se eximir da sua responsabilidade pelas questões sociais, seguido da legitimação da lógica neoliberal, favorecida pelo enfraquecimento das políticas sociais, pela privatização das organizações estatais e do enxugamento dos gastos públicos. Nessa lógica, o Estado é minimizado e as respostas às questões sociais são transferidas para a sociedade civil (empresarial ou não), que vende ou fornece gratuitamente os serviços sociais.

Montaño (2007) aborda o conceito do terceiro setor como algo que supera a dicotomia público/privado (Estado/Mercado) e que traz respostas que o próprio Estado não consegue atender e o mercado já não busca responder. No entanto, o terceiro setor deve ser 
considerado como parte do "primeiro", não como parte da sociedade civil. No atendimento das questões sociais, as ONGs figuram como um assistencialismo ultrapassado, que no caso do Brasil desorganizam profissões, estruturante para a atuação do Estado, como Estado de direito e responsável pela garantia dos direitos de todos.

Após o posicionamento de Montaño (2007), aponta-se que a concepção utilizada para a condução deste artigo parte da relevância dos trabalhos das ONGs, que está contida na atuação junto às causas de enfrentamento de problemas que vão desde o enfoque social ao ambiental e em áreas de responsabilidade do governo como alimentação, habitação, saúde, educação e meio ambiente. As ONGS atuam na defesa de causas (advocacy) e na prestação de serviços à população, assim como também contribuem para fortalecer os programas públicos para a provisão de serviços já existentes. A prestação de serviços por parte das ONGs favorece a interligação entre quem recebe e oferta os serviços, entre comunidades e outros setores e beneficiários e os demais provedores (OLIVEIRA; FERRAZ, 2007). Além do mais, as ONGs colaboram para o progresso socioeconômico, uma vez que contribuem com a oferta de serviços e de know-how (FIFKA et al., 2016).

Embora a importância das ONGs seja reconhecida, estas organizações enfrentam o desafio da gestão com recursos limitados para realizar os seus projetos e para a sua manutenção (CARVALHO\& FADUL, 2012), as dificuldades na gestão organizacional e na alocação de recursos humanos qualificados. Tais desafios impactam diretamente no funcionamento das ONGs e dificultam a realização das suas atividades. Estes podem ser minimizados se desenvolvida a capacidade gerencial dessas instituições (FIGUEIREDO et al, 2013; FALCONER, 1999).

Entende-se que, mesmo com a crescente profissionalização da gestão dessas instituições, aliar os aspectos conceituais e a prática gerencial com o modo de gestão das ONGS é um desafio a ser superado (FIGUEIREDO et al, 2013). O modo de gestão das ONGs perpassa pela temática da qualidade na prestação de serviços.

A definição da qualidade remete à adequação ao uso, ao fornecimento de bens e serviços isentos de erros e em conformidade com os propósitos dos consumidores (SLACK; CHAMBERS;JOHNSTON, 2009). No caso dos serviços, a avaliação da qualidade acontece ao longo da sua prestação. Autores apontam que existe dificuldade em mensurar e manter a qualidade em virtude da natureza do produto. Assim, o principal indicador da qualidade poderá ser definido com base nas expectativas dos clientes (ARAÚJO; COSTA; ALMEIDA, 2013).

Os conceitos apresentados tomam por referência a avaliação do cliente que paga pela prestação de serviços e os recebe. Entretanto, remetem à lógica das empresas que operam no 
mercado, em que a lucratividade e o crescimento da organização estão ligados à satisfação do cliente. No caso do terceiro setor, não há uma relação direta com o consumidor, uma vez que o beneficiário direto não paga pelo serviço (HECKERT; SILVA, 2008).

As organizações do terceiro setor recebem recursos de diversas fontes para manter as suas atividades e grande parte do custeio não vem do consumidor direto do serviço, o beneficiário, mas do financiador. As organizações se constituem e são mantidas a partir das relações de trocas. Nas empresas atuantes no mercado, estas relações são firmadas em valores financeiros. Já nas organizações do terceiro setor, os valores estabelecidos são não-financeiros, ou seja, os doadores ofertam dinheiro e tempo em troca de reconhecimento, gratidão ou satisfação das necessidades psicológicas. E os beneficiários recebem os serviços sem dar uma contrapartida tangível à organização (HECKERT; SILVA, 2008).

Com as interações entre financiadores e beneficiários, faz-se necessário tratar da qualidade dos serviços prestados pelas organizações. No que diz respeito à qualidade de serviços aplicada ao terceiro setor, devem ser consideradas as características próprias destas organizações, em que é preciso definir quem é o cliente, para encontrar a melhor maneira de atender às suas necessidades; identificar as expectativas e percepções do cliente para atendê-lo de maneira satisfatória; e definir o objetivo da avaliação da qualidade, com o cuidado de identificar as expectativas e percepções dos beneficiários (HECKERT; SILVA, 2008).

As organizações do terceiro setor buscam a satisfação dos seus beneficiários e o reconhecimento dos seus parceiros, que acontece quando os padrões mínimos de qualidade dos serviços prestados são atingidos. Para que isso aconteça, é necessária a implementação de um sistema de gestão da qualidade que assegure o cumprimento dos requisitos dos serviços, assim como a satisfação dos beneficiários e o reconhecimento externo (CARVALHO; FERREIRA; LIMA, 2012).

As pressões pela qualidade dos serviços prestados pelas organizações nãogovernamentais surgem dos seus clientes e do público em geral, que buscam a resolução dos problemas sociais. E para atender às pressões, as organizações adotam modelos próprios da gestão empresarial, como a gestão da qualidade total, o balanced scorecard, o benchmarking, entre outros. Salienta-se que a adoção de sistemas de gestão da qualidade traz benefícios além da vantagem competitiva e contribui para a garantia da sustentabilidade (CARVALHO et al., 2012).

Ao observar a qualidade na prestação de serviços nas empresas, a melhoria da qualidade está implícita na atração de clientes e no aumento da lucratividade. Já no terceiro setor, contraditoriamente, como a prestação de serviços é gratuita e/ou subsidiada, ao atrair 
mais clientes, estas organizações têm aumento nos seus custos. Mesmo que haja ganhos auferidos com a eficiência operacional, a qualidade não poderá ser abordada sem o cuidado de observar os impactos nas finanças da organização. Além disso, deve ser seguido do aumento da captação de recursos - para não comprometer a sua sustentabilidade financeira. No terceiro setor, a qualidade deve enfocar o usuário e valor, ou seja, satisfazer as necessidades a um preço aceitável (HECKERT; SILVA, 2008). Falconer (1999) ainda aponta que a melhoria da qualidade dos serviços deverá ser um aprimoramento contínuo dos entes que compõem o terceiro setor, que não podem estar acomodados e devem enfrentar os problemas sociais.

Assim, inicialmente o artigo traz a abordagem das principais temáticas que servem de base conceitual para a sua construção. Posteriormente, apresenta-se a descrição da metodologia utilizada para a realização deste trabalho. Adiante, apresentam-se os resultados alcançados, as considerações finais e as referências utilizadas para dar base a este estudo.

\section{MATERIAIS E MÉTODOS}

Este artigo é resultado do projeto de extensão Gestão de Serviços em Instituições do Terceiro Setor, aprovado no edital do Programa Institucional de Bolsa de Extensão (BEXT) no ano de 2016, pela Pró-Reitoria de Extensão da UFRPE e com vigência de janeiro a dezembro de 2017.

A equipe executora do projeto foi composta de quatro docentes do curso de Bacharelado em Administração, três alunas do curso de graduação em Administração e três estudantes do mestrado em Administração e Desenvolvimento Rural (PADR/UFRPE) e uma mestra em Administração e Desenvolvimento Rural. O projeto ainda contou com o apoio de outros profissionais das áreas de saúde, meio ambiente, beleza e alimentação. Como resultado do desenvolvimento do planejamento do projeto, podemos elencar três etapas norteadoras para sua realização: seleção das instituições, diagnóstico organizacional e execução de ações. Estas etapas, juntamente com o período de realização, estão representadas no quadro 1.

Quadro 1:Etapas de Realização do Projeto

\begin{tabular}{|c|c|c|c|}
\hline \multicolumn{5}{|c|}{ ETAPAS DO PROJETO } \\
\hline Fase & Seleção das Instituições & Diagnóstico Organizacional & Execução das atividades \\
\hline $\begin{array}{c}\text { Atividades } \\
\text { desempenhadas }\end{array}$ & $\begin{array}{c}\text { Seleção dos participantes } \\
\text { Processo seletivo }\end{array}$ & Coleta de dados & $\begin{array}{c}\text { Elaboração e execução do } \\
\text { plano de ação }\end{array}$ \\
\hline $\begin{array}{c}\text { Período de } \\
\text { realização }\end{array}$ & Fevereiro de 2017 & Abril e Maio de 2017 & $\begin{array}{c}\text { Junho a Novembro de } \\
2017\end{array}$ \\
\hline
\end{tabular}

Fonte: Dados da Pesquisa (2018) 
Na primeira fase, foi realizada a divulgação de forma on-line e em reuniões da Rede Pernambuco Voluntários. Ao todo, 12 entidades se inscrevam para a seleção para participação do projeto através de um questionário on-line e, posteriormente, foram convidadas para entrevistas presenciais seletivas com os seus respectivos gestores.

As entrevistas tinham por objetivo apresentar a proposta do projeto de extensão e conhecer as organizações. Durante esse momento foi possível preencher um questionário com dados gerais das instituições, obtendo-se algumas informações significativas sobre elas. A partir dos dados coletados e avaliados, e pela observação da equipe que conduziu as entrevistas. Ao fim, foram selecionadas 5 instituições, que cumpriram os requisitos para participar do projeto.

Os critérios de seleção para as instituições foram: estar localizadas na Região Metropolitana do Recife; ser favorável à implementação das ações propostas pela equipe executora do projeto; não ter ligação com político ou ser fruto de atividade política; e não pertencer a instituição religiosa. Os representantes das instituições selecionadas assinaram um termo de compromisso, no qual constava as principais obrigações dos participantes do projeto, como a realização das atividades propostas pela equipe, frequência acima de $75 \%$ nas oficinas de formação, disponibilidade em atender às necessidades do projeto e o comprometimento em aplicar os conhecimentos disponibilizados pelos extensionistas.

$\mathrm{Na}$ segunda etapa, a sistemática utilizada para a coleta de dados que subsidiou a construção do diagnóstico organizacional foi pautada em entrevistas com os gestores das organizações participantes do projeto, aplicação de questionário e a observações realizadas durante três visitas. O questionário empregado foi desenvolvido pela equipe do projeto, nele constavam itens sobre: identificação da ONG e do gestor entrevistado; as atividades ofertadas pelas instituições; os recursos humanos e como ocorria o seu gerenciamento; o ponto de vista do entrevistado sobre a atuação da organização; espaço para observações dos entrevistadores; e questões sobre o desenvolvimento das atividades de gestão da organização.

Os dados coletados nessa etapa possibilitaram o desenvolvimento de relatórios sobre a situação organizacional das instituições. Essas informações foram discutidas e avaliadas com os gestores das organizações, o resultado dessa etapa foi a elaboração de planos de ação de cada instituição visando a melhoria de alguns gargalos que impactavam na qualidade dos serviços prestados. Os principais pontos de melhoria encontrados através dos diagnósticos foram: dificuldades na captação de recursos financeiros; baixa qualificação da equipe; ineficiência na gestão de voluntários; e ausência de um plano de marketing institucional.

De posse dos relatórios e dos planos de ação, iniciou-se a terceira e última fase do projeto: a execução das ações de melhoria. A equipe de extensionistas elaborou um plano de 
ação da sua equipe para apoiar algumas das atividades que deveriam ser desenvolvidas pelas instituições. $\mathrm{O}$ objetivo do plano de ação do projeto era agrupar as necessidades das entidades para que tarefas pudessem ser promovidas pela equipe de extensão e seus parceiros. Entretanto, puderam-se observar dificuldades na execução devido às diferenças entre as necessidades das ONGs participantes, aliada à necessidade de realizar ações individuais personalizadas, e a restrição de recursos humanos, materiais e financeiros do projeto de extensão. A seção a seguir traz os resultados deste artigo.

\section{RESULTADOS E ANÁLISES}

O Plano Nacional de Extensão (Brasil, 2001) traz como princípio para formação do profissional cidadão que é imprescindível sua interação com a sociedade. Neste sentido, o projeto de extensão intitulado "Gestão de Serviços em Instituições do Terceiro Setor", aprovado pela Pró-Reitoria de Extensão da Universidade Federal Rural de Pernambuco, com vigência de janeiro a dezembro de 2017, teve o objetivo de promover ações de consultoria e capacitação em gestão de serviços para cinco instituições do terceiro setor (OTS), localizadas na região metropolitana do Recife, buscando o incremento da sustentabilidade destas. Os objetivos propostos visavam promover a melhoria da gestão organizacional, dando suporte administrativo para as instituições estudadas.

Com isso, o público-alvo do projeto compreendeu os colaboradores e beneficiários de cinco instituições, que por sua vez, atendem cada qual a diferentes públicos-alvo, conforme detalhado no Quadro 2, que apresentam as características das instituições atendidas, de acordo com os dados da pesquisa realizada.

Quadro 2 - Características das instituições atendidas pelo projeto de extensão

\begin{tabular}{|c|c|l|l|}
\hline INST. & FUNDAÇÃO & \multicolumn{1}{|c|}{ RECURSOS HUMANOS } & \multicolumn{1}{|c|}{ PÚBLICO-ALVO } \\
\hline 1 & 2003 & $\begin{array}{l}10 \text { funcionários e entre 15 a 20 } \\
\text { voluntários. }\end{array}$ & $\begin{array}{l}\text { Usuários de drogas lícitas e ilícitas e } \\
\text { seus familiares. }\end{array}$ \\
\hline 2 & 2003 & $\begin{array}{l}8 \text { funcionários, sendo 2 prestadores de } \\
\text { serviços e 2 voluntários. }\end{array}$ & $\begin{array}{l}\text { Crianças e adolescentes em situação } \\
\text { de vulnerabilidade. }\end{array}$ \\
\hline 3 & 1991 & $\begin{array}{l}11 \text { funcionários e entre 10 a 15 } \\
\text { voluntários. }\end{array}$ & $\begin{array}{l}\text { Crianças que sofreram situações de } \\
\text { riscos graves e alta complexidade. }\end{array}$ \\
\hline 4 & 1985 & 86 funcionários e 325 voluntários. & $\begin{array}{l}\text { Crianças e adolescentes em } \\
\text { tratamento oncológico. }\end{array}$ \\
\hline 5 & 1995 & $\begin{array}{l}10 \text { funcionários, 1 estagiário e 9 } \\
\text { voluntários. }\end{array}$ & $\begin{array}{l}\text { Empreendedores de pequenos } \\
\text { negócios. }\end{array}$ \\
\hline
\end{tabular}

Fonte: Dados da Pesquisa (2018)

Inicialmente, para conhecermos melhor as suas necessidades, foram coletados dados in loco que nos permitiram traçar um diagnóstico que revelou as principais dificuldades que as 
OTS possuem no desenvolvimento de suas atividades, destacando-se: dificuldade na arrecadação e administração de recursos financeiros; pouca qualificação do pessoal administrativo; dificuldade na gestão de equipe de voluntários; deficiência na divulgação dos serviços prestados; e falta de atualização das rotinas trabalhistas. Essas dificuldades constituem desafios à gestão das OTS que impactam diretamente o desenvolvimento das suas atividades como apontado no referencial (FIGUEIREDO et al., 2013; CARVALHO; FADUL, 2012; FALCONER, 1999;).

Para vencer esses desafios, no que diz respeito à gestão, cabe a discussão do papel dos líderes dessas organizações, que na maioria das vezes têm formação diversa à sua atuação e que também na maioria das vezes não conhece as ferramentas de gestão para aplicar à instituição, conforme a sua necessidade. Nessa seara, entende-se que é fundamental a presença de um profissional habilitado para assumir tal função, como o administrador, que conforme pesquisa do Conselho Federal de Administração (2016), congrega as seguintes características: otimizador da utilização de recursos e com foco em resultados; formador, líder e motivador de equipes; profissional que atua com a visão do todo da organização; e articulador e coordenador dessas áreas, e que pode, com os conhecimentos adquiridos em sua formação, realizar um trabalho agregador nas instituições sem fins lucrativos.

Assim, conhecendo a situação atual, definimos as prioridades e elaboramos planos de ações contendo as atividades desempenhadas pelo projeto. Foi utilizada a ferramenta $5 \mathrm{~W} 2 \mathrm{H}$ para detalhar o planejamento das ações do projeto ${ }^{1}$. O Quadro 3 aponta as dificuldades encontradas e as ações propostas pela equipe para trabalhar alguns pontos das organizações, conforme demanda, de acordo com os dados auferidos durante o ano 2017.

Quadro 3 - Principais dificuldades administrativas encontradas

\begin{tabular}{|c|c|c|}
\hline INST & DIFICULDADES ADMINISTRATIVAS & AÇÕES PROPOSTAS \\
\hline 1 & $\begin{array}{l}\text { - Baixa qualificação profissional; } \\
\text { - Desconhecimento da legislação específica do } \\
\text { terceiro setor e geral; } \\
\text { - Escassez de recursos financeiros; } \\
\text { - Falta de apoio por meio de incentivos fiscais. }\end{array}$ & $\begin{array}{l}\text { - Oficina de Relacionamento Interpessoal } \\
\text { - Plano de Marketing } \\
\text { - Pesquisa de Satisfação e Qualidade dos Serviço } \\
\text { - Qualidade no Atendimento }\end{array}$ \\
\hline 2 & $\begin{array}{l}\text { - Baixa qualificação profissional; } \\
\text { - Desconhecimento da construção de um plano } \\
\text { de voluntários; } \\
\text { - Dificuldade no planejamento de ações de } \\
\text { marketing na instituição; } \\
\text { - Falha no arquivamento dos documentos. }\end{array}$ & $\begin{array}{l}\text { - Organização dos Documentos } \\
\text { - Semana de Qualidade de Vida } \\
\text { - Qualidade no Atendimento }\end{array}$ \\
\hline 3 & - Baixa qualificação profissional; & - Oficina de Relacionamento Interpessoal \\
\hline
\end{tabular}

\footnotetext{
${ }^{1}$ As ferramentas utilizadas na realização do projeto não têm diferenças na sua utilização, podendo ser aplicadas tanto em instituições sociais quanto nas instituições privadas ou públicas. A adoção da ferramenta de gestão apenas elenca, a partir das suas questões, meios para a construção de um plano de ação. No caso do projeto, as questões do método direcionaram a construção do plano de ação para atuação nas organizações.
} 


\begin{tabular}{|c|c|c|}
\hline & $\begin{array}{l}\text { - Escassez de recursos financeiros; } \\
\text { - Desconhecimento da construção de um plano } \\
\text { de voluntários. }\end{array}$ & $\begin{array}{l}\text { - Plano de Voluntário } \\
\text { - Semana de Qualidade de Vida } \\
\text { - Plano de Marketing } \\
\text { - Qualidade no Atendimento }\end{array}$ \\
\hline 4 & $\begin{array}{l}\text { - Dificuldade na captação de recursos } \\
\text { financeiros permanentes; } \\
\text { - Falta de um sistema integrado que interligue } \\
\text { os setores da instituição; } \\
\text { - Insuficiência de capacitações e treinamentos } \\
\text { para os funcionários. }\end{array}$ & $\begin{array}{l}\text { - Diagnóstico da Redução das Doações } \\
\text { - Sistema Integrado de Gestão } \\
\text { - Qualidade no Atendimento }\end{array}$ \\
\hline 5 & $\begin{array}{l}\text { - Desatualização de práticas no departamento } \\
\text { pessoal; } \\
\text { - Desconhecimento de maiores técnicas de } \\
\text { atendimento e cobrança aos clientes; } \\
\text { - Falhas na comunicação interna. }\end{array}$ & $\begin{array}{l}\text { - Oficina de Relacionamento Interpessoal } \\
\text { - Plano de Marketing } \\
\text { - Rotinas Trabalhistas e Técnicas de Cobrança } \\
\text { - Qualidade no Atendimento }\end{array}$ \\
\hline
\end{tabular}

Fonte: Dados da Pesquisa (2018)

Conhecendo as dificuldades, especificamente na área de gestão de pessoas, a equipe do projeto ofereceu Oficina de Relacionamento Interpessoal para três instituições (Instituições 1, 3 e 5). Foram observadas as falhas na comunicação existentes entre diretores e funcionários das instituições, o que apontou a necessidade de se instituir canais de comunicação regulares, tais como, reuniões periódicas, onde se abordam as principais questões com o intuito de ouvir os problemas e levantar as soluções. Também foi observada a relevância dos colaboradores para a saúde das instituições, sendo necessária a constante supervisão e atenção da diretoria na realização de cursos de qualificações dos seus profissionais, além da promoção de momentos de descontração e lazer, reconhecendo-os e motivando-os em seu trabalho. Ao final, a oficina de comportamento organizacional mostrouse uma ferramenta eficiente, reforçando a importância das relações interpessoais e do fortalecimento da cultura organizacional, identificando os problemas e gerando soluções que podem ser implantadas pelas instituições.

$\mathrm{Na}$ instituição 4, foi relatada a necessidade de se fazer um Diagnóstico das Causas da Redução das Doações. Desta forma, foi aplicado um questionário com as atendentes do telemarketing da ONG. Foram respondidos 17 questionários. Resumindo os dados da pesquisa, observou-se que as causas da redução são várias, tais como a situação econômica desfavorável. A segunda maior dificuldade foi a de "cadastro telefônico desatualizado". Através dos questionários também foram mencionados "telefones bloqueados ou não existem". É importante ressaltar que a "doação a outras ONGs" foi a terceira dificuldade mais citada. O item 5, falta de estrutura, diz respeito às informações "Não ter celulares suficientes para as operadoras" e "Demora para entrega do boleto". A ação 2 foi de extrema importância para a Instituição, pois foi informado aos membros da instituição as principais causas das diminuições de doações; foram sugeridas algumas ações para melhoria do processo de 
captação, como: treinamento específico para os operador de telemarketing; melhorias na estrutura de trabalho, como cadastro telefônico atualizado e aquisições de telefones móveis.

O Plano de Voluntário é um documento de orientação para gestão do programa de voluntariado das instituições atendidas. O plano é composto do detalhamento de alguns processos necessários à gestão desta equipe tão importante. Iniciou com o processo de recrutamento, deixando claro que o primeiro passo é realizar o mapeamento das vagas existentes e depois a definição dos canais utilizados para divulgação das vagas. O segundo passo é a seleção dos voluntários como uma forma de direcionar a pessoa adequada para a execução das atividades específicas. São sugeridas algumas etapas nesta fase: preenchimento da ficha de cadastro do candidato; agendamento do dia e hora da entrevista; entrevista simples com avaliação do currículo. Nesta ocasião, deve-se falar sobre as várias oportunidades oferecidas a voluntários, valendo-se da descrição específica de tarefas. No processo de admissão, deve ser apresentada ao candidato a Lei do Serviço Voluntário, para que tome conhecimento de seus direitos e deveres, além do Termo de Adesão ao Serviço Voluntário e o regimento interno da organização, o termo que equivale ao contrato de trabalho numa empresa; este documento deve ser assinado por ele no seu primeiro dia de trabalho voluntário.

No plano foi ressaltada a importância do treinamento para o sucesso da equipe de voluntários, dando dicas de alguns temas. Sugeriu-se um acompanhamento do trabalho prestado pelo voluntário, como forma de estabelecer uma avaliação de desempenho e a utilização de alguns canais de comunicação com a equipe de voluntários (Whatsapp, Facebook, emails e quadro de avisos). Alguns modelos de formulários foram anexados no documento entregue às $O N G$ 's: termo de adesão; termo de desligamento; certificado de participação; ficha cadastral de voluntário; fichas de avaliação e modelos de frequências. Esta ação foi desenvolvida na Instituição 3.

A ação de Organização dos Documentos foi desenvolvida na Instituição 2, pois ela necessitava organizar a documentação institucional e de seus beneficiários, além da documentação trabalhista. Foi uma ação que demandou uma dedicação da equipe e os resultados não foram totalmente alcançados, houve uma limitação de recursos materiais e humanos.

A Semana de Saúde e Qualidade de Vida foi realizada nas Instituições 2 e 3, nos dias 05 e 06 de dezembro de 2017, com o objetivo de promover a integração entre a equipe do projeto, parceiros (convidados), os funcionários e beneficiários das $\mathrm{ONG}^{\prime}$ s e de oferecer dois dias diferentes com ações de beleza, saúde, alimentação saudável e técnicas de preparação de alimentos, ginástica laboral e recreação, além de oferecer uma oficina de horta. Foi um 
momento de grande descontração e de aprendizagem para todos, para quem deu e recebeu as atividades.

A necessidade de elaboração de um Plano de Marketing foi diagnosticada para as Instituições 1, 3 e 5, porém, após análise dos recursos disponíveis para comunicação externa, com a ajuda da assessoria da área de comunicação da Companhia Hidroelétrica do São Francisco (Chesf), a equipe achou melhorar simplificar o instrumento apresentando um plano simplificado de captação de recursos e de comunicação.

A Pesquisa de Satisfação na Qualidade de Serviço foi solicitada pela Instituição 1, pois a mesma possui espaços de recuperação de dependentes químicos e gostaria de medir a satisfação dos beneficiários com os serviços prestados. A equipe executora do projeto elaborou uma pesquisa de satisfação seguindo a metodologia criada pelos autores Parasuraman, Zeithaml e Berry (1985), a SERVQUAL, baseada nas cinco dimensões da qualidade. A saber: Tangibilidade, Confiabilidade, Responsividade, Adequabilidade e Empatia. O método consiste em mensurar a qualidade do serviço, baseando-se nas expectativas do cliente em contraponto com a percepção que esse mesmo cliente tem em relação ao serviço que recebeu. Para isso foram construídos dois questionários, um de expectativa e outro de percepção. Cada um continha 22 perguntas referentes às cinco dimensões da qualidade. As questões deveriam ser avaliadas pelo grau de importância do respondedor, seguindo uma escala ordinal de 1 a 5 , sendo considerado (1) Pouquíssimo importante, (2) Pouco importante, (3) Média importância, (4) Muito importante e (5) Muitíssimo importante.Por fim, foi elaboradoum questionário final da avaliação da qualidade dos serviços que tem por finalidade mensurar a média das proposições dos questionários anteriores e destacar as lacunas existentes nos itens avaliados. Isto permite à instituição interpretar o que está sendo valorizado pelo beneficiário, levando-os a adotar uma estratégia para responder às necessidades destes.

A Instituição 4 tinha uma deficiência no seu processo de comunicação interna, principalmente na atualização das informações para Call Center e para os órgãos parceiros, necessitava de um Sistema Integrado de Gestão com dados dos beneficiários, dos recursos humanos e financeiros. Como a equipe de extensão era formada por alunas e professoras dos cursos de Graduação em Administração e do mestrado acadêmico em Administração e Desenvolvimento Rural, a demanda do sistema não foi plenamente atendida, a equipe tentou diversas parcerias com a empresa júnior do curso de Bacharelado em Ciência da Computação, porém, sem sucesso, pois o sistema deveria ser gratuito e o período para o desenvolvimento da aplicação demandaria um período de tempo que excederia o projeto, e que quiçá deveria ser objetivo de um projeto de extensão. 
A instituição 5 era a instituição com a maior necessidade de capacitação de pessoal, pois trabalhava com crédito popular. Foi montado um plano de capacitação de funcionários com os seguintes treinamentos: cursos de Rotinas Trabalhistas e Técnica de Cobrança; oficina de comportamento; treinamento motivacional com uma profissional de recursos humanos e capacitação de qualidade no atendimento. Os cursos de rotinas trabalhistas e de técnicas de cobrança não foram realizados. A equipe do projeto buscou uma parceria com o Serviço Nacional de Aprendizagem Comercial (SENAC) para ministrar os dois cursos, porém o valor cobrado pela instituição foi superior ao que a ONG poderia custear e os recursos financeiros do projeto não eram suficientes para contratação dos cursos.

O curso de Qualidade no Atendimento foi oferecido em parceria com o Serviço Brasileiro de Apoio às Micro e Pequenas Empresas (SEBRAE) e obteve uma avaliação positiva dos participantes das instituições (dessa ação participaram as instituições 1 e 5 ).

O projeto foi de extrema relevância para todos os envolvidos, tanto para as organizações participantes do projeto, quanto para as extensionistas, uma vez que permitiu aos integrantes a aplicação dos conteúdos das disciplinas da graduação em Administração, assim como foi possível a realização de uma troca de conhecimentos entre as Organizações Não Governamentais e a academia, a aprendizagem foi levada para sala de aula, havendo a junção da extensão com o ensino. Durante a execução do projeto, foi permitido às estudantes e professoras integrar conhecimentos de diversas áreas da administração, como: marketing, finanças, gestão de pessoas (comportamento organizacional) e organização, sistemas e métodos (gestão de processos).

Outro ponto importante do projeto de extensão foi o convívio entre alunas do mestrado e da graduação, a vivência foi salutar. Houve o planejamento e a gestão do projeto com cronograma e orçamento. Cada aluna ficou responsável por uma instituição, no entanto,todas ajudaram na execução das atividades. Só assim foi possível realizar tantas ações, atender cinco organizações no período de 1 ano (janeiro a dezembro de 2017).

O feedback das instituições atendidas pelo projeto de extensão "Gestão de Serviços em Instituições do Terceiro Setor" foi obtido pelo questionário de avaliação estruturado com 20 perguntas. Conforme dados obtidos, o projeto de forma geral alcançou os resultados esperados, considerado com "Bom" e "Muito bom", a equipe do projeto foi avaliada como excelente, principalmente no que diz respeito a empenho e que o projeto melhorou a imagem da Universidade frente à comunidade. Ficou clara a satisfação com os facilitadores das capacitações pela disponibilidade e compreensão com o público, levando a reflexões e muitas 
vezes inspirando o público atendido. Como sugestões foram apontadas: ter uma avaliação pósprojeto e um acompanhamento na execução de algumas ações contínuas.

Como aspecto negativo, pode ser elencado o tempo disponível para o projeto, pois algumas ações solicitadas pelas instituições tinham a duração superior a um ano. Houve dificuldades financeiras para implementar algumas das atividades, já que a verba disponibilizada para o projeto não foi suficiente para tal. Além do mais, algumas demandas dos participantes do projeto, como formações específicas em áreas de atuação das ONGs, não puderam ser atendidas em função das limitações da equipe e da falta de parceiros disponíveis para tal atividade. No caso das ONGs, pode-se relatar a falta de estrutura de algumas das instituições para realização das atividades do projeto.

Com relação à integração entre pesquisa e extensão, o projeto apresentado está gerando produções científicas, como a aprovação de um artigo enviado para o Congresso Internacional de Administração (ADMPG 2018) e quatro resumos completos apresentados na XVII Jornada de Ensino, Pesquisa e Extensão - JEPEX, em 2017, com os seguintes temas: relato de experiência do projeto de extensão; o desenvolvimento da oficina de comportamento organizacional; os desafios na captação de recursos para o Terceiro Setor e, por fim, a exposição do modelo de diagnóstico organizacional para a prestação de serviços desenvolvido pela equipe executora do projeto. Estão também sendo finalizados dois artigos para serem enviados aos eventos acadêmicos e futuramente trabalhados para publicação em periódicos científicos.

\section{CONSIDERAÇÕES FINAIS}

O presente artigo, que relata o Projeto de Extensão intitulado "Gestão de Serviços em Instituições do Terceiro Setor", contribuiu para enfatizar a importância da realização de projetos de extensão envolvendo instituições não governamentais. $O$ projeto relatado aproximou a academia da sociedade, melhorando a imagem da Universidade. Ademais, as ideias das ferramentas e ações executadas pelo projeto podem ser replicadas em outras organizações auxiliando na melhoria das atividades desenvolvidas por elas.

Fica bem claro que a equipe, composta por professoras e alunas dos Cursos de Graduação em Administração e da Pós-graduação em Administração e Desenvolvimento Rural, aprendeu bastante sobre as dinâmicas das ONG's, ao trabalharem com cinco instituições de segmentos distintos, observando suas semelhanças na forma de atuação e nas suas dificuldades na manutenção das atividades desenvolvidas para o público-alvo e suas 
diferenças, algumas organizações religiosas com culturas bem específicas. Houve um enriquecimento sobre a área da Administração, um aprendizado proporcionado pela apropriação de conhecimentos provenientes de várias disciplinas do Curso de Administração, contemplando, também, outras áreas de estudos, constituindo um enriquecimento transversal e interdisciplinar do conhecimento.

Outro ponto a destacar foi o projeto ter permitido um crescimento atitudinal nas alunas por vários motivos: a) desafio de planejar e gerenciar um projeto com uma equipe grande e com cinco instituições atendidas; b) gerenciamento de conflitos e gerenciamento de tempo e de opiniões; c) resistência à frustração, já que por vezes reuniões foram canceladas e houve opiniões divergentes, envolvendo a prática da resiliência; d) envolvimento e comprometimento com os resultados e com os prazos; e) entendimento de diversas realidades e o sentimento de empatia.

Por outro lado, o projeto de extensão realizado gerou impactos na gestão das ONG's. A equipe do projeto elaborou, juntamente com a equipe das instituições atendidas, um diagnóstico organizacional com propostas de melhorias. Durante o período do projeto, foram realizadas algumas ações com impacto direto na sustentabilidade das organizações, e, consequentemente, uma melhoria na qualidade dos serviços prestados. Dentre as demais ações relatadas, é bom enfatizar a oficina de comportamento que levou o grupo a uma reflexão sobre a forma que as atividades estavam sendo desenvolvidas. Na avaliação final do projeto, todas as instituições mencionaram sua satisfação com relação ao projeto de forma geral, quanto aos serviços prestados e à equipe do projeto da UFRPE.

Quanto ao uso das ferramentas de intervenção utilizadas durante o projeto, como o 5W2H e o SERVQUAL, compreende-se foram adequadas para o trabalho com instituições do terceiro setor, não ficando restritas apenas ao seu uso dentro da esfera privada. O seu uso atendeu às necessidades identificadas pela equipe executora e gerou resultados relevantes para o projeto.

Quanto à integração entre ensino, pesquisa e extensão, essa foi bem visível durante o projeto, muitas das experiências vividas nele foram utilizadas como exemplos em sala, ajudando na compreensão da teoria e vice-versa. Os conhecimentos estudados em sala foram aplicados nos diagnósticos, planos de ação e na execução das atividades do projeto. Com relação à pesquisa, o projeto fez surgir outros temas de pesquisa e artigos para congressos, os quais futuramente, com seu aperfeiçoamento, serão enviados para periódicos.

As limitações do trabalho foram o cronograma, com muitas ações para pouco tempo, sendo que o projeto tem duração de 12 meses. Também a necessidade de realizar parcerias 
para execução de algumas atividades, sem sucesso, pois envolvem custos altos. E ainda a dificuldade de acompanhar a continuidade das ações após o término do projeto.

Com futuros trabalhos, sugerem-se o relato das oficinas de relacionamento interpessoal, bem com a aplicação de uma avaliação de resultados para mensurar o real impacto do projeto após a sua conclusão.

\section{AGRADECIMENTOS}

As autoras agradecem à Coordenação de Aperfeiçoamento de Pessoal de Nível Superior (CAPES) pela concessão de bolsa de pesquisa e à Universidade Federal Rural de Pernambuco, pela aprovação do projeto de extensão e concessão da bolsa de extensão.

\section{REFERÊNCIAS}

AL-TABBA, O.; LEACH, D.; MARCH, J. CollaborationBetweenNonprofitand Business Sectors: a frameworktoguidestrategydevelopment for nonprofitorganizations. Voluntas: InternationaljournalofOrganization, TheoryandBehavior, 25 (3), p 657-678, 2014. Disponível em: https://goo.gl/YYvjPN Acesso em 08 ago. 2018.

ARAÚJO, M. M.; COSTA, J. A. F.; ALMEIDA, M. R. Qualidade em serviços e o comportamento servidor: Estabelecendo uma relação teórica. Anais do XXXVII Encontro Nacional da Associação Nacional de Pós-Graduação e Pesquisa em Administração. Rio de Janeiro, RJ, Brasil, 2013. Disponível em: https://goo.gl/egmUK9 Acesso em: 02 jun. 2018.

CARvalho, A. O.; FADUl, E. M. C. Os Fatores Críticos de Sucesso na Gestão das Organizações Não-Governamentais. Administração Pública e Gestão Social, v.4, p.148-171, 2012. Disponível em: https://goo.gl/nZuyTk Acesso em: 30 maio 2018.

CARVALHO, A.; FERREIRA, M.; LIMA, V. A qualidade no Terceiro Setor: o caso do Centro de Reabilitação Profsissional de Gaia (GRPG). In Anais do IV Congresso Internacional de Casos Docentes em Marketing Público e Não Lucrativo, Porto, Portugal, 2012. Disponível em: https://goo.gl/ABLmPa Acesso em: 30 maio 2018.

CONSELHO FEDERAL DE ADMINISTRAÇÃO. Pesquisa Nacional Sistema CFA/CRA: perfil, formação, atuação e oportunidades de trabalho do administrador e tecnólogo (6a. ed.). Brasília, DF, Brasil: Angrad, 2016.

FALCONER, A. P. A. Promessa do terceiro setor: um estudo sobre a construção do papel das organizações sem fins lucrativos e do seu campo de gestão, Dissertação de Mestrado, Faculdade de Economia, Administração e Contabilidade da Universidade de São Paulo, São Paulo, SP, Brasil, 1999. 
FIGUEIREDO, V. C.; SOUZA, A. A. A.; SILVA, I. C. M., ROSA, M. E. A.; GAMA, M. C. B.; SETTE, R. S. Dificuldades de Gestão das Organizações Não Governamentais: Uma Nova Configuração do Modelo de Trabalho. In Anais do IV Encontro de Gestão de Pessoas e Relações de Trabalho, Brasília, DF, Brasil, 2013. Disponível em: https://goo.gl/Z2hvoE Acesso em 29 maio 2018.

FIFKA, M. S.; KÜHN, A.L.; ADAUI, C. R. L.; STILGLBAUER, M.PromotingDevelopment in WeakInstitutionalEnvironments: The UnderstandingandTransmissionofSustainabilityby NGOS in LatinAmerica. Voluntas: InternationalJournalofVoluntaryandNonprofitOrganizations, vol. 27, p. 1091-1122, 2006. Disponível em: https://goo.gl/EX1Xgs Acesso em 29 maio 2018.

HECKERT, C. R.; SILVA, M. T. Qualidade de Serviços nas Organizações do Terceiro Setor. Produção, vol. 18, n. 2 p. 319-330, 2008. Disponível em: https://goo.gl/qj7zxR Acesso em: 30 maio 2018.

MONTAÑO, Carlos. Terceiro setor e questão social; crítica ao padrão emergente de intervenção social. São Paulo: Cortez, 2002.

OLIVEIRA, C. A.; JR.; FERRAZ, S. F. S. ONGS Como Espaço de Investimento Profissional. Anais do XXXI Encontro Nacional da Pós-Graduação em Administração da Associação da ANPAD. Rio de Janeiro, RJ, Brasil, 2007. Disponível em: https://goo.gl/E3mAHJ Acesso em: 30 maio 2019.

PARASURAMAN, A.; ZEITHAML, V. A. \& BERRY, L. L. A Conceptual ModelOf Services QualityAnd Its Implication For Future Research. Journalof Marketing, vol. 49, n.4 p. 41-50, 1985.

PLANO NACIONAL DE EXTENSÃO UNIVERSITÁRIA. Fórum de Pró-Reitores de Extensão das Universidades Públicas Brasileiras. [Coleção Extensão Universitária] (Vol. 1). Ilhéus: Editus, 2001.

SLACK, N.; CHAMBERS, S. \& JOHNSTON, R. Administração da Produção. 3. ed. São Paulo: Editora Atlas, 2009.

TENÓRIO, F. G. Gestão de ONGS: principais funções gerenciais. 11. ed. Rio de Janeiro: Editora FGV, 2009.

TEODÓSIO, A. S. S. Pensar pelo avesso o terceiro setor: mitos, dilemas e perspectivas da ação social organizada nas políticas sociais. Revista Lusotopie, PUC-MG, n.1, p. 241-262, 2002. Disponível em: https://goo.gl/GaU4CB Acesso em 18 jun. 2018.

Recebido em: 10/09/2019

Aceito em: 19/06/2020 